DOI: https://doi.org/10.47405/mjssh.v6i11.1134

\begin{tabular}{|c|c|}
\hline 4 & Malaysian Journal of Social Sciences and Humanities (MJSSH) \\
\hline $\begin{array}{l}\text { Malaysian Juoural of } \\
\text { Social ccciecces and }\end{array}$ & Volume 6, Issue 11, November 2021 \\
\hline (MJ-sSH) & e-ISSN : 2504-8562 \\
\hline & $\begin{array}{l}\text { Journal home page: } \\
\text { www.msocialsciences.com }\end{array}$ \\
\hline
\end{tabular}

\title{
The Impact of CO2 Emissions on the GDP per Capita, Employment Rate and Energy Consumption of China, Korea and Japan
}

\author{
Allieah A. Mendoza1, Kirby Duane Garret T. Reyes', Pauline Antonette D. Soriano, \\ Ronaldo R. Cabauatan 1,2,3 \\ ${ }^{1}$ College of Commerce of Business Administration, University of Santo Tomas, Manila, Philippines \\ ${ }^{2}$ Research Center for Social Sciences and Education, University of Santo Tomas, Manila, Philippines \\ ${ }^{3}$ The Graduate School, University of Santo Tomas, Manila, Philippines \\ Correspondence: Ronaldo Cabauatan (rrcabauatan@ust.edu.ph)
}

\begin{abstract}
This paper aims to investigate the relationship between CO2 Emissions and GDP per capita of three East Asian countries (China, Japan, and South Korea). The Environmental Kuznets Curve hypothesis and its possible implications to the implementation of the Kyoto Protocol Agreement will be tested. The independent variables Employment and Energy consumption will be used as control variables. Multiple regression analysis and cointegration tests will be used on time series data of Japan, Korea, and China that is obtained from the World Bank database. GDP per capita is measured in constant 2010 US\$, CO2 emission in kt, Employment in the ratio of total employment to total population aged 15 and above, and Energy Consumption in annual kWh per capita.
\end{abstract}

Keywords: $\mathrm{CO} 2$ emission, GDP per capita, employment rate, energy consumption, environmental Kuznets curve

\section{Introduction}

The primary component of global warming is the exponential rise in the ratio of gases in the environment that causes the greenhouse effect. The greenhouse effect is a natural phenomenon that causes the Earth's surface temperature to rise. When sunlight reaches the Earth's atmosphere, part of it is reflected back into space, while the remainder is absorbed and re-radiated by greenhouse gases. The temperature of the earth's surface rises as carbon dioxide $(\mathrm{CO} 2)$ and methane gas levels increase in the atmosphere. $\mathrm{CO} 2$, which is released into the atmosphere from burning fossil fuels such as oil, coal, and natural gas, is the primary gas that induces the greenhouse effect that was mostly used to increase productivity (Yildirim, 2017). The levels of $\mathrm{CO} 2$ and other gases in the atmosphere traps the solar radiation surrounding the Earth's surface, causing global warming. These may signify that the sea levels are rising to the point that it will be able to inundate many cities situated on the coast in the coming decades. Furthermore, this phenomenon has the potential to wreak havoc on the international agricultural and trade systems (Carvalho \& de Almeida, 2011). The countries will go through stages of growth, driven by market forces and changes in government regulations. Economic growth in the first stage, marked by the transition from an agricultural to an industrialized economy, imposes a strain on the environment as a result of the establishment and expansion of manufacturing plants. The literature on this subject has been rapidly growing since Grossmann and Krueger $(1991,1993,1995)$ introduced the inverted U-shaped association between gross domestic product and environmental quality at the 
beginning of the 1990s, along with the serious increasing environmental degradation (Carvalho \& de Almeida, 2011).

The Environmental Kuznets Curve is used to model the relationship between economic development and environmental quality. According to the model, development and growth of countries have three phases. In the first phase, the transition from agricultural to industrial activities result in economic growth and worsening environmental quality. Countries increase economic activity and, at the cost of environmental quality. Countries use fossil fuel because it is more sustainable and cheaper. $\mathrm{CO} 2$ emissions increase as a result of the use of fossil fuels. As industrial activities expand in the second phase, environmental quality continues to worsen. However, the decline is at a slower pace as pollution reduction measures and technologies become available. Countries in the second phase experience economic development in a specific manner. The countries achieve a certain degree of economic advancement. On the other hand, it has extremely increased $\mathrm{CO} 2$ emissions. In the third phase, the relationship between economic growth and reverses. Economies have achieved substantial development allowing them to continue expansion while improving environmental quality. The country's ability to boost economic growth resulted in a reduction in $\mathrm{CO} 2$ emissions (Thongrawd \& Kerdpitak, 2020). In the first stage, marked by the transition of an agricultural economy to an industrialized one, the economic growth implies a pressure on the environment, as a consequence of creation and expansion of manufacturing plants. At the moment, meeting basic needs allows for the expansion of industries that are less resource and emissions intensive. Simultaneously, technical advancement continues to reduce energy intensity. Finally, in the third development stage, the positive relationship between economic growth and environmental quality will be severed, as the former does not indicate an increase in the latter (Carvalho \& de Almeida, 2011).

Many developed, as well as developing countries, signed the Kyoto protocol to protect nature and avoid the fatal consequences of uncontrolled energy consumption and economic development (Hasanov, Mikayilov, Mukhtarov, \& Suleymanov, 2019). The Kyoto Protocol, which was first adopted on December 11, 1997, commits 39 developed countries to reduce emissions of four greenhouse gases (GHGs) by 5.2 percent on average between 2008 and 2012, compared to 1990 levels. It was available for signature from March 16 to March 15, 1999. 84 signatures were collected by the Kyoto Protocol during this time span. Just Belarus, Hungary, and Iceland did not sign the protocol, out of 39 countries with reduction commitments (Almer \& Winkler, 2012). The protocol divided countries into two categories: Annex-B with GHG emissions reduction obligations and the Non-Annex-B without emission reduction obligations (Grunewald \& Zarzoso, 2010). Only Annex I countries were subject to emission restrictions under the protocol. Non-Annex I countries took part by participating in initiatives aimed at reducing pollution in their own countries. Developing countries received carbon credits for these programs, which they could exchange or offer to develop countries in exchange for a higher level of maximum carbon emissions for that duration (Wang, Ko, \& Jiun, 2019).

In addition, this function benefited developing countries in continuing to emit GHG at a high rate. In 2001, the United States, which had signed the initial Kyoto Agreement, terminated the arrangement. According to Hovi, Skodvin and Andresen (2009), the United States thought the agreement was unreasonable since it only required developed nations and exempted developing nations to curb carbon reductions, which it claimed would damage the US economy and it was discovered that developing countries are gradually adding to global pollution where $\mathrm{CO} 2$ emissions from emerging countries have been quickly surpassing those of developed countries, which accounted for almost $50 \%$ of the world's $\mathrm{CO} 2$ in 2003.

Despite being implemented in 1997, global emissions were still rising in 2005, the year the Kyoto Protocol became international law. Although several nations, including those in the EU, seemed to be doing well. By 2011, they expected to meet or surpass the agreement's goals. On the other hand, other nations appeared to come up short. The China and the United States, two of the world's largest emitters, managed to generate enough greenhouse gases to balance out any improvements achieved by countries that meet their goals. In addition, between 1990 and 2009, global pollution increased by around 40\% (Hovi, Skodvin, \& Andresen, 2009). 
In December 2012, Annex and Non-annex parties discussed an extension of the initial Kyoto agreement in Doha, Qatar, after the first agreement duration ended. The Doha Amendment set new emission-reduction goals for participating countries for the second commitment duration covering 2012 to 2020. The Doha Amendment allows surplus Assigned Amount Units (AAUs) from the first commitment cycle to be carried through, but it restricts their usage for offsetting emission growth beyond commitment levels. For countries that pledged a growth goal under the Kyoto Protocol's second commitment period, Amendment concurrently "shaves" AAU allocation to an amount equal to average 2008-2010 emissions. This means that economies in transition (EITs) are not given growth flexibility, resulting in commitments that are vastly different from their initial pledges. The EU's "bubble" agreement raises doubts about whether new Member States can avoid "shaving" due to their shared goal. As a consequence of the Doha Amendment, Annex I EITs will be in an unfair position (Korppoo, 2013).

In 2015, almost every country signed the Paris Climate Agreement, which is a historic environmental agreement. According to Newell, Pizer, \& Raimi, (2012) all major GHG-emitting countries have agreed to reduce their climate-altering emissions as part of an agreement. The main fundamental principle of the agreement is to reduce global GHG pollution in order to keep the earth's temperature growth in this century to no more than 2 degrees Celsius above pre-industrial levels and taking steps to keep the rise to 1.5 degrees Celsius (Streck, Keenlyside, \& Unger, 2016). According to Winning, Price, Ekins, Pye, Glynn, Watson, and McGlade (2019), deferring increased intervention until 2030 limits global economic growth beyond 2030, resulting in a global GDP that is $1.6 \%$ in 2050 than the optimum $2^{\circ} \mathrm{C}$ trajectory from 2020, and 5.6 percent lower than the NDC baseline. These detrimental effects persist until 2050, and the economic disparity persists (Winning, et al., 2019).

\section{Literature Review}

\section{Theoretical Framework}

Environmental Kuznets curve theory can be used to predict trends in $\mathrm{CO} 2$ emission patterns and economic growth. The EKC turning points are a viable predictor of policy effects on a panel of homogeneous countries in terms of wealth, energy, and policy, and thus even to individual countries with persistent economic structure. It hypothesizes that income gap rises and then falls in industrializing nations Inequality rises as rural labor migrates to urban regions and becomes socially mobile. Countries which are categorized in different classes due to different economic backgrounds can create an effective policy with the help of the environmental Kuznets curve as it can help in educating employees and or laborers on their environmental obligations and responsibilities enhancing the cost control of lowering the number of incidents being produced those results in liability of preserving natural resources and energy. According to Wang, Ko, and Jiun, (2019), the EKC Hypothesis explains the relationship between economic development and environmental depletion in terms of per capita income. Per capita income and environmental degradation are said to have an inverse U-shaped relationship. According to the theory, as per capita income increases, environmental degradation rises at first and then begins to decline after reaching a maximum level of degradation (Grunewald \& Zarzoso, 2010).

Grossman and Krueger (1994) found no evidence that economic growth causes irreversible harm to the natural environment, Instead, they discovered that, while rises in GDP can be correlated with deteriorating environmental conditions in very poor countries, after a certain level of income is achieved, air and water quality tend to benefit from economic development. According to Pata (2018), the EKC hypothesis was validated by empirical results. According to Maitah, Toth and Kuzmenko, (2015), when implementing economic policies, the consistency of the relationship between these variables is critical and to ensure sufficient jobs in a world where the working-age population is rapidly growing, development must be maintained as well as at high rates. 


\section{GDP per Capita to CO2 emissions}

Du, Wei, and Cai (2012) found a positive relationship between CO2 emissions and economic growth using the series of static and dynamic panel data models covering the years 1995 to 2009. The estimations shows that economic development, technology progress and industry structure hardly affect China's $\mathrm{CO} 2$ emissions, while the impacts of energy consumption structure, trade openness and urbanization level are negligible. The calculation results do not strongly support the inverted U-shaped relationship between per capita $\mathrm{CO} 2$ emissions and economic growth trend. Saboori and Sulaiman (2013) showed a significant non-linear relationship between carbon emissions. Economic growth was supported in Singapore and Thailand for the long run which supports the Environmental Kuznets Curve (EKC) hypothesis.

Ejuvbekpokpo (2014), Kasperowicz (2015) and Nguyen (2019) revealed that CO2 emissions have negative impact on economic growth. $\mathrm{CO} 2$ emissions should be reduced because it has been defined as a determinant leading to a decrease in economic growth. According to the study of Ejuvbekpokpo (2014), carbon emissions also have negative impact on gross domestic product in Nigeria and have adverse effect on the level of gross domestic product (GDP) through reduction in aggregate output in the Nigerian economy.

Asumadu-Sarkodie and Owusu (2017) used the autoregressive distributed lag model from Rwanda by employing a time series data spanning from 1965 to 2011. The study shows that carbon dioxide emissions, GDP per capita, industrialization and population are co-integrated and have a long-run equilibrium relationship. They found that 1 percent increase in GDP per capita leads to a decrease of $\mathrm{CO} 2$ emissions by 1.45 percent, but a 1 percent increase in industrialization will increase $\mathrm{CO} 2$ emissions by 1.64 percent in the long run. This also support the validity of the environmental Kuznets curve hypothesis. According to the study of Kasperowicz (2015), the relationship between GDP and $\mathrm{CO} 2$ emissions is negative, because the development of new low-carbon technologies enables in the long-run reaching the same production level at lower $\mathrm{CO} 2$ emissions. The estimation of GDP long-run equation indicated that that the $\mathrm{CO} 2$ emissions are negatively related to economic growth, which was confirmed by panel cointegration test results.

Tong, Ortiz, Xu, and Li (2020) and Alshehry and Belloumi (2017) stated that CO2 emissions and GDP show neutral relationship using bootstrap autoregressive distributed lag (ARDL) bound test with structural breaks covering the annual data from 1971 to 2014, except for Russia (1992-2014) because of data irregularities, the results shows that there is no cointegration between economic growth, energy consumption, and $\mathrm{CO} 2$ emissions for China, Indonesia, Mexico, and Turkey. Results also indicated that energy consumption, energy price, carbon dioxide emissions, and economic growth have at least a long-run equilibrium relationship. For Saudi Arabia, there is a unidirectional causality from energy demand to economic growth in the short and long run. Reduction of energy consumption and CO2 emissions could slow economic growth, but not significantly.

\section{GDP per Capita to Employment Rate}

Employment related economic indicators, particularly those that measure the ability of economies to generate sufficient employment opportunities for their populations, often provide valuable insights to the economies overall macroeconomic performance. Among the most widely publicized indicators along these lines are unemployment rates, employment to population rations, and labor force participation rates. According to Kapsos (2006), another evident economic problem which is employment outweighs all those in the socioeconomic sphere. The increase in unemployment is approximately equal to the change in employment in the short run with labor force participation. The net gain in unemployment and employment is progressing more slowly (Kitov \& Kitov, 2011). According to Maitah, Toth and Kuzmenko, (2015), there is a positive correlation between GDP per capita and employment rate; for example, a $2 \%$ increase in GDP per capita contributes to a $1 \%$ increase in employment, this relationship also applies vice versa. 
Kapsos (2006) demonstrated that total employment increased by 0.3 to 0.38 percentage points for every one percentage point increase in GDP growth. This indicates that productivity gains accounted for roughly two-thirds of economic growth between 1991 and 2003, with expanded labor supply accounting for the remaining one-third. Employment growth was highest in the period from 1995 to 1999, which also coincided with the strongest global economic growth. According to Kitov, Ivan, and Oleg, (2011), using an adjusted Okun's law for the employment/population ratio in the United States, the shift in employment/population ratio was observed and anticipated. The discrepancy between 1979 and 1983 as approximate break years may be due to the influence of measurement noise on leastsquares method performance. The workforce/population ratio increased from 57 percent in 1982 to 63 percent in 1989, according to the figures. The change in slope is identical, suggesting that the change, both the rate of employment and the rate of unemployment are more responsive to the rate of change in GDP.

In Canada, a structural break occurs in 1984, as demonstrated by a slight adjustment in slope and intercept. The employment-to-population ratio ranges from $4.5 \%$ in 1971 to $64.1 \%$ in 2008 . The months prior 1984, the relationship mandated GDP growth rates to be greater than $1.27 \%$ per year in which for the employment rate to rise. Otherwise, the employment rate will decrease, and the unemployment rate will increase. In France, however, the process of least squares applied to the integral form of Okun's law yields different modeling results. Except for the 1982 shift in the job rate, the change in the unemployment rate is more unpredictable. This is a strictly random change from 53.2 percent in 1981 to 55.3 percent in 1982. As a result, Okun's law for France does not match the findings. This result can also be seen in the change in the rate of employment and the negative rate of unemployment in Japan, demonstrating that the latter variable is as unpredictable as the former and differs significantly, in contrast to the coordinated evolution of these variables in the United States As a result, the data is unable to obtain a fair Okun's law for Japan (Kitov \& Kitov, 2011).

\section{GDP per Capita to Energy Consumption}

Energy is a key source of economic growth because many production and consumption activities involve energy as a basic unit of input. Energy is one of the most important inputs for economic development. The use of energy is the indispensable factor of economic productivity and industrial growth, and it is central to the operation of any modern economy and as economies grow, energy demand increases; if energy is constrained, GDP growth pulls back in turn. According to Esen and Bayrak (2017), with the use of panel data analysis for 75 net energy importing countries for the period of 1990-2012, they discovered that a $1 \%$ rise in energy consumption raises GDP per capita by 0.36 percent for all net energy-importing countries, 0.47 percent for countries with less than $50 \%$ import dependence, and 0.31 percent for countries with more than $50 \%$ import dependence. If we divide the net energy importers by income class, we get 0.14 percent for low-income economies, 0.37 percent for lower-middle-income economies, 0.25 percent for upper-middle-income economies, and 0.48 percent for high-income economies. Except for upper-middle-income and high-income economies, the shortrun parameter of energy consumption is statistically insignificant.

$\mathrm{Li}$ et al. (2011) stated that in 30 provinces in China using the regression analysis for the period of 1970-2005 showed that the long-run co-integration have a positive relationship between the real GDP per capita and energy consumption. According to Kais and Sami (2015), using the Generalized method of moments (GMM) for period 1990-2012 showed that the impact of the financial development on energy consumption is positive and statistically significant only for the global panel, for the Europe and North Asia, and for the Latin American and Caribbean region as greater financial development leads to an increase in energy consumption. Financial systems finances businesses and industries, resulting in increased employment and, as a result, increased economic activity and domestic trading.

Azlina, Law, Hashim and Mustapha (2014) used time series data during periods 1975-2011, empirical outcomes indicates that Malaysia variables of energy consumption in the transportation sector, income and $\mathrm{Co} 2$, are intertwined with the previous studies that explored the validity of the emission-growth nexus and the energy-growth nexus in the same setting. As a result, the variables as mentioned above have a long-run relationship. Increases in income and energy consumption in the transportation sector 
raise $\mathrm{CO} 2$ emissions by 2.56 percent and 0.44 percent, respectively. Results implied that there is a unidirectional causality that exists from emission to income, energy consumption and renewable energy consumption.

According to Mohanty and Chaturvedi (2015), the KPSS test was applied to annual data for India from 1970-1971 to 2011-2012, revealed the existence of long-run and short-run causality going from energy usage to economic growth with no substantial impact; an increase in energy demand is accountable for increasing economic growth. The findings rejected the neoclassical principle of energy consumption neutrality. Also, because causality in India runs from electricity consumption to GDP, electricity consumption is a limiting factor for GDP growth. Same results were also obtained by Ozturk, Aslan, and Kalyoncu (2010) using the panel threshold regression approach using the sample for 53 countries from periods 1999-2008 have ascertained that there is long-run Granger causality running from GDP to energy consumption in low-income countries, and bidirectional causality between energy consumption and GDP for middle-income countries.

Chang (2014) used the panel threshold regression approach with data for 53 countries for periods 1999-2008 suggested that the sample can be divided into two regimes: high and low income. In emerging market and developing economies, energy consumption rises with income, whereas in established countries, energy consumption rises with income when the economy reaches a certain level of income. Furthermore, when both private and domestic credit are utilized as financial development indicators in the non-high income regime, energy consumption rises with financial growth. When the value of traded equities and stock market turnover are considered as financial development indicators, however, it marginally drops with financial development in advanced economies, particularly in the United States. Second, energy consumption per capita continues to grow in the advanced economies, especially in high-income countries, as incomes increase. The explanation appears to be that energysaving technical innovations tend to allow a greater number of energy-using appliances to be introduced into households and industries (causing more energy consumption), as the money saved is spent on other goods and services. Finally, in the non-high-income regime, energy consumption increases with financial development when both private and domestic credit are used as financial development indicators. Financial systems that are sound and efficient—banks, equities markets, and bond markets - that route capital to its most productive uses are advantageous to economic growth. As Financial development also encourages growth by increasing competition and fostering creative activities that increase dynamic efficiency. And with a rise in credit could lead to a rise in the purchase and consumption of energy-consuming commodities, creating environmental degradation.

According to Pata (2018) using the data for periods 1996-2014 for the 23 sub-Saharan African countries, the outcomes of three cointegration tests showed that these variables of per capita GDP, per capita carbon dioxide (CO2) emissions, financial development, per capita total renewable energy consumption, hydropower consumption, alternative energy consumption and urbanization had a longrun relationship. The ARDL coefficients, which are completely modified least squares (FMOLS), and canonical cointegrating regression (CCR) estimators revealed that economic growth, financial development, and urbanization all contribute to environmental degradation, while total renewable energy consumption, hydroelectric consumption, and alternative energy consumption had no impact on CO2 emissions. Bilgili, Kocak and Bulut (2014) used panel data collection of 17 OECD countries from year 1977 to 2010 and performed panel FMOLS and panel DOLS estimations showed that GDP per capita and GDP per capita squared have both positive and negative effects on $\mathrm{CO} 2$ emissions. respectively, and that the use of renewable energy has a detrimental effect on $\mathrm{CO} 2$ emissions.

The findings of the empirical study conducted by Mohanti and Chaturvedi (2015) is in consensus with the earlier findings except for Işık and Shahbaz (2015) using Pedroni panel cointegration and causality technique from the data range 1980-2010 for the OECD countries. OECD countries will need more energy in the future, possibly requiring the development of alternative and low-cost energy sources in manufacturing processes. The OECD countries will fail to grow nonrenewable resources for future generations unless they take the requisite measures and precautions in the procurement of sustainable energy sources and environmental policies. Furthermore, the panel analysis results support the causality running between energy consumption and economic growth, suggesting that energy 
conservation policies in OECD countries could sustain economic growth. The EKC hypothesis states that economic growth will lead to reduction in emissions. On the contrary, Narayan and Popp (2012) used the univariate and panel LM-Lagrange multiplier for 17 middle eastern countries for the periods of 1980-2009, with the results gathered it points out that in the national level states that energy consumption has a negative causal effect on actual GDP and found important evidence that energy consumption has a negative Granger impact on real GDP for the G6 panel of countries.

\section{Research Method}

This study estimated the relationship between economic growth and $\mathrm{CO} 2$ emission for 3 selected East Asian countries which are China, Japan, and Korea. The independent variables employment and energy consumption were used to get a better estimate of the impact and to lessen errors in the econometric model. Multiple regression analysis and cointegration tests were employed to analyze 3 selected Asian countries over the period 1977- 2014 for Japan and Korea and 2000-2014 for China. GDP per capita (constant 2010 US\$) was used as a measurement for economic growth, CO2 emission (kt) for $\mathrm{CO} 2$ emission, employment to population ratio, 15+, total (\%) (national estimate) for employment and electric power consumption (kWh per capita) for energy consumption on an annual basis. The data have been obtained from the World Bank database.

\section{Augmented Dickey-Fuller (ADF)}

Most economic time series data have unit roots which show that their means and variances are not time-invariant. If this is the case, a univariate series is said to be non-stationarity and cannot be used for regression with other non-stationary univariate series because of the risk that their results maybe spurious. The only exception to this rule is when the time series data of all variables have identical unit roots.

The widely used unit root test is the so-called Augmented Dickey-Fuller (ADF) test. The basic equation for testing the stationarity of a time series is given by the following:

$\Delta x=\alpha_{o}+\alpha_{l} t+\beta x_{t-i}+\Sigma \varphi \Delta x_{t-i}+\varepsilon_{t}$

where the first difference of the series, $\Delta \mathrm{x}_{\mathrm{t}}$, is regressed against lagged of its original level series, time, and lagged values of itself. If the estimated value of $\beta$ is more negative than MacKinnon critical values, the series is said to be stationary. Otherwise, it is non-stationary and therefore has a unit root. The augmented portion of the test is to correct for any serial correlation in the variable.

\section{Causality Test}

The Standard Granger test is a commonly used method of determining if two variables are causally related. If past values of a variable $\mathrm{Y}$ substantially led to determining the value of another variable $\mathrm{Xt}+1$, then $\mathrm{Y}$ is said to thus affect Granger influence $\mathrm{X}$, and vice versa. Krueger (2008) discovered a unidirectional Granger causality in a groundbreaking analysis (Ejuvbekpokpo, 2014).

$$
\begin{gathered}
\Delta \text { LGDPPC }_{i t}=\sum_{k=1}^{p} \beta_{k} \Delta L G D P P C_{i, t-k}+\sum_{k=0}^{p} \theta_{k} \Delta C O 2 \text { emission }_{i, t-k}+u_{i, t} \\
\Delta C O 2 \text { emission }_{i t}=\sum_{k=1}^{p} \beta_{k} \Delta C O 2 \text { emission }_{i, t-k}+\sum_{k=0}^{p} \theta_{k} \Delta \text { LGDPPC }_{i, t-k}+v_{i, t} \\
\text { LLDPPC }_{i t}=\sum_{k=1}^{p} \beta_{k} \Delta L G D P P C_{i, t-k}+\sum_{k=0}^{p} \theta_{k} \Delta \text { employment }_{i, t-k}+u_{i, t}
\end{gathered}
$$




$$
\begin{aligned}
& \text { semployment }_{i t}=\sum_{k=1}^{p} \beta_{k} \Delta \text { employment }{ }_{i, t-k}+\sum_{k=0}^{p} \theta_{k} \Delta \operatorname{LGDPPC}_{i, t-k}+v_{i, t} \\
& \Delta L G D P P C_{i t}=\sum_{k=1}^{p} \beta_{k} \Delta L G D P P C_{i, t-k}+\sum_{k=0}^{p} \theta_{k} \Delta \text { energy use } e_{i, t-k}+u_{i, t} \\
& \Delta \text { energy use } e_{i t}=\sum_{k=1}^{p} \beta_{k} \text { senergy use } e_{i, t-k}+\sum_{k=0}^{p} \theta_{k} \Delta L G D P P C_{i, t-k}+v_{i, t}
\end{aligned}
$$

\section{Structural Stability test}

Structural stability test refers to the stability of the coefficients of a regression model between different time periods. In this study, such test will be performed using Chow Breakpoint Test. A structural change could mean a change in the intercept, a change in the slope coefficients, or a change in both the intercept and slope coefficients. Either way, the results would imply structural instability and the model therefore cannot be used for policy analysis and forecasting.

The formula for testing the structural stability of the regression parameter involving time series data is as follows:

$$
F=\frac{\left(R S S_{R}-R S S_{U R}\right) / k}{R S S_{U R} /\left(n_{1}+n_{2}-2 k\right)}
$$

where $\mathrm{k}$ is the number of regressors including intercept, $\mathrm{n}$ is the number of observations, $\mathrm{RSS}_{\mathrm{R}}$ is the regression sum of squares restricted, and $\mathrm{RSS}_{\mathrm{UR}}$ is the regression sum of squares unrestricted. If the computed F-statistic exceeds critical value, there is structural instability. Otherwise, the model is said to be structurally stable.

\section{Test for Heteroskedastic Disturbances}

If the variance of the regression residuals of the model is time varying, the parameters and their standard errors are said to be biased and inefficient. This condition is known as heteroskedasticity and if uncorrected could lead to wrong conclusions and decisions on the part of the investigator. To detect the presence of heteroskedastic disturbances in the residuals, the White Heteroskedasticity Test will be used.

$u^{2}=\alpha_{o}+\alpha_{1} X_{1}+\alpha_{2} X_{2}+\alpha_{3} X_{3}+\alpha_{4} X_{1}^{2}+\alpha_{5} X_{2}^{2}+X_{3}^{2}+\alpha_{6} X_{1} X_{2}+\alpha_{7} X_{1} X_{3}+\alpha_{8} X_{2} X_{3}+v_{t}$

where $\mathrm{u}^{2}$ is the squared regression residuals regressed against the explanatory variables, their squares, and cross products.

\section{Optimal Lag Length}

An efficient test in determining the optimal lag length is to minimize the Akaike Information Criterion (AIC), Schwarz Information Criterion (SIC), or Bayesian Information Criterion (BIC) for each lag length on a trial-and-error basis. For the Akaike Information Criterion (AIC) which is a popular test, the formula is as follows:

$\ln A I C=(2 k / n)+\ln (R S S / n)$ 
where $\mathrm{k}$ is the number of regressors including intercept, $\mathrm{n}$ is number of observations, and RSS is regression sum of squares. After experimenting with a sufficient number of lags in the model, the one which produces the smallest AIC would indicate the appropriate or optimal lag length.

\section{Johansen Cointegration Test}

In applying the Johansen Cointegration Test which consists of five options, although options 1 and 5 are avoided because of their explosive values which are not consistent with economic realities, such options were utilized according to the Dickey-Pantula principle by beginning with the most restrictive (Option 2) down to the least restrictive (Option 4).

If the computed trace statistics and maximum-eigenvalue statistics exceed their critical values, then there is cointegration among the variables. The hypothesized relationships cannot be deemed spurious and therefore genuine equilibrium relationships existed.

\section{Specification Error test}

The Ramsey regression equation specification error test (RESET) will be used to test whether nonlinear combinations of independent variables help in explaining the dependent variable. This will also help determine if there is no misspecification error in the data used in the study.

A Specification error test is associated with the specification of the model regarding the inclusion of an irrelevant variable, the exclusion of relevant variable, or the functional form of the model. A Specification error creates biased or inconsistent regression estimators, and the inconsistency can still be there even when the sample observation increases. To determine the specification of the model, this study used the equation:

$$
\hat{Y}_{i}=\hat{\beta}_{1}+\hat{\beta}_{2} X_{2 i}+\hat{\beta}_{3} X_{3 i}+\gamma \hat{Y}_{i}^{2}
$$

\section{Results and Discussion}

Table 1 shows the results of the unit root test for Japan at level, first difference, and second difference. Table 2 shows that there is no multicollinearity among the variables as shown by the VIF and the regression residual achieved normality as shown by the Jarque-Bera stat. Moreover, there is no autocorrelation error as shown by the Durbin-Watson stat and no serial correlation as shown by the Breusch-Godfrey Serial Correlation LM Test. Additionally, results show that there is no heteroskedasticity error encountered in the regression using Heteroskedasticity Breusch-PaganGodfrey test and the ARCH test. Lastly, there is no structural breakpoint in the results as shown by the Chow breakpoint test and there is no misspecification error encountered in the regression as shown by the RAMSEY Reset test. Table 2 also shows that the second difference of $\log \mathrm{CO} 2$ emissions and the second difference of employment to population ratio are positively significant to first difference of log GDP per capita. When $\mathrm{CO} 2$ emission and employment to population ratio increases, GDP per capita increases as well. Similar to the study of Du, Wei, and Cai (2012) which found a positive relationship between CO2 emissions and economic growth in China and the study Kapsos (2006) which stated that economic growth and employment rate have a positive relationship, as economic growth increases, employment increases as well. However, this contradicts the study of Kitov and Kitov (2011) which stated that there is a negative relationship between economic growth and employment rate. If there is an increase in economic growth then there is a decrease in employment. Contrary to the study of Nguyen (2019) stating that CO2 emissions have negative impact on economic growth and CO2 emissions should be reduced because it has been defined as a determinant leading to a decrease in economic growth. 

DOI: https://doi.org/10.47405/mjssh.v6i11.1134

Table 1: Unit root test: Japan

\begin{tabular}{|c|c|c|c|c|c|c|}
\hline Variable & Level & Prob & $\begin{array}{l}\text { First } \\
\text { Difference }\end{array}$ & Prob & $\begin{array}{l}\text { Second } \\
\text { Difference }\end{array}$ & Prob \\
\hline $\begin{array}{l}\text { Log electric power } \\
\text { consumption per capita }\end{array}$ & -2.483308 & 0.1276 & -0.940284 & 0.7620 & -5.709524 & $0.0000 * * *$ \\
\hline Log C02 emission & 1.165829 & 0.6787 & -6.361643 & $0.0000^{* * *}$ & -3.982140 & $0.0045^{* * *}$ \\
\hline $\begin{array}{l}\text { Employment to } \\
\text { population ratio }\end{array}$ & -1.177379 & 0.6735 & -3.054141 & $0.0402 * *$ & -4.073833 & $0.0036^{* * *}$ \\
\hline Log GDP per capita & 4.218241 & $0.0021 * * *$ & -3.896517 & $0.0050 * * *$ & -6.510117 & $0.0000 * * *$ \\
\hline
\end{tabular}

Table 2: Regression results: Japan

Dependent Variable: D(LOGGDP_PER_CAPITA)

Sample: 19882014

\begin{tabular}{llllll}
\hline Variable & Coefficient & Std. Error & t-Statistic & Prob. & VIF \\
\hline \hline Constant & 0.010488 & 0.002191 & 4.786637 & 0.0001 & NA \\
$\begin{array}{l}\text { D(D(LOGELECTRIC_POWER_CONSUM } \\
\text { PTION)) }\end{array}$ & 0.130612 & 0.077900 & 1.676646 & 0.1072 & 1.848069 \\
D(D(LOGCO2_EMISSIONS)) & 0.339562 & 0.074186 & 4.577194 & 0.0001 & 1.928063 \\
D(D(EMPLOYMENT_TO_POPULATION & & & & & \\
_RATIO)) & 0.021321 & 0.004695 & 4.541292 & 0.0001 & 1.129523 \\
\hline \hline R-squared & 0.833138 & Mean dependent var & 0.012913 & \\
Adjusted R-squared & 0.811373 & S.D. dependent var & 0.022707 & \\
S.E. of regression & 0.009862 & Akaike info criterion & -6.264289 & \\
Sum squared resid & 0.002237 & Schwarz criterion & -6.072313 & \\
Log likelihood & 88.56790 & Hannan-Quinn criter. & -6.207204 & \\
F-statistic & 38.27942 & Durbin-Watson stat & 2.163737 & \\
Prob(F-statistic) & 0.000000 & & & & \\
Jarque-Bera Stat & 0.817483 & & & & \\
Prob(Jarque-Bera) & 0.664486 & & & & \\
\hline \hline
\end{tabular}

Breusch-Godfrey Serial Correlation LM Test:

Null hypothesis: No serial correlation at up to $1 \mathrm{lag}$

F-statistic 0.254652

Prob. $\mathrm{F}(1,22)$

0.6188

Heteroskedasticity Test: Breusch-Pagan-Godfrey

Null hypothesis: Homoskedasticity

F-statistic

2.220574 Prob. $\mathrm{F}(3,23)$

0.1130

Heteroskedasticity Test: ARCH

F-statistic $\quad 0.998087$

Prob. $F(1,24)$

0.3277

Chow Breakpoint Test: 2001

Null Hypothesis: No breaks at specified breakpoints

F-statistic $\quad 0.486327$

Log likelihood ratio $\quad 2.631844$

Wald Statistic $\quad 1.945308$

Prob. F(4,19) $\quad 0.7456$

Prob. Chi-Square(4) 0.6212

Prob. Chi-Square(4) $\quad 0.7458$

\begin{tabular}{lllc}
\hline \hline Ramsey RESET Test & & & \\
& Value & df & Probability \\
\cline { 2 - 4 } t-statistic & 0.851464 & 22 & 0.4037 \\
F-statistic & 0.724991 & $(1,22)$ & 0.4037 \\
Likelihood ratio & 0.875416 & 1 & 0.3495 \\
\hline \hline
\end{tabular}

Table 3 shows the cointegration results for Japan indicating that the variables are cointegrated in the long-run. This shows that the variables are related in the long-run and can be use in the regression. 
Table 4 shows that the second difference log GDP per capita Granger Cause second difference log electric power consumption in Japan. Similarly, first difference log GDP per capita Granger Cause second difference $\log \mathrm{CO} 2$ emissions which is similar to the study of Saboori and Sulaiman's (2013) which found to have a bi-directional Granger causation links between economic growth and $\mathrm{CO} 2$ emissions, along with economic growth and energy consumption in Indonesia, Malaysia, and the Philippines. The absence of short-term causality from economic growth to $\mathrm{CO} 2$ emissions implies that economic growth is not a suitable strategy for reducing $\mathrm{CO} 2$ emissions in the short-run. However, there is no causation between first difference log GDP per capita and second difference of log employment to population ratio contrary to Kitov and Kitov (2011) that there is a negative association between economic growth and employment rate.

Table 3: Cointegration Test: Japan

\begin{tabular}{|c|c|c|c|c|}
\hline Hypothesized & Trace & & Max-Eigen & \\
\hline No. of CE(s) & Statistic & Prob.** & Statistic & Prob.** \\
\hline None * & 97.95461 & 0.0000 & 37.59681 & 0.0019 \\
\hline At most $1 *$ & 60.35780 & 0.0000 & 35.97291 & 0.0002 \\
\hline At most $2 *$ & 24.38489 & 0.0018 & 21.37695 & 0.0032 \\
\hline At most 3 & 3.007934 & 0.0829 & 3.007934 & 0.0829 \\
\hline
\end{tabular}

Sample: 19772014

Table 4: Granger causality: Japan

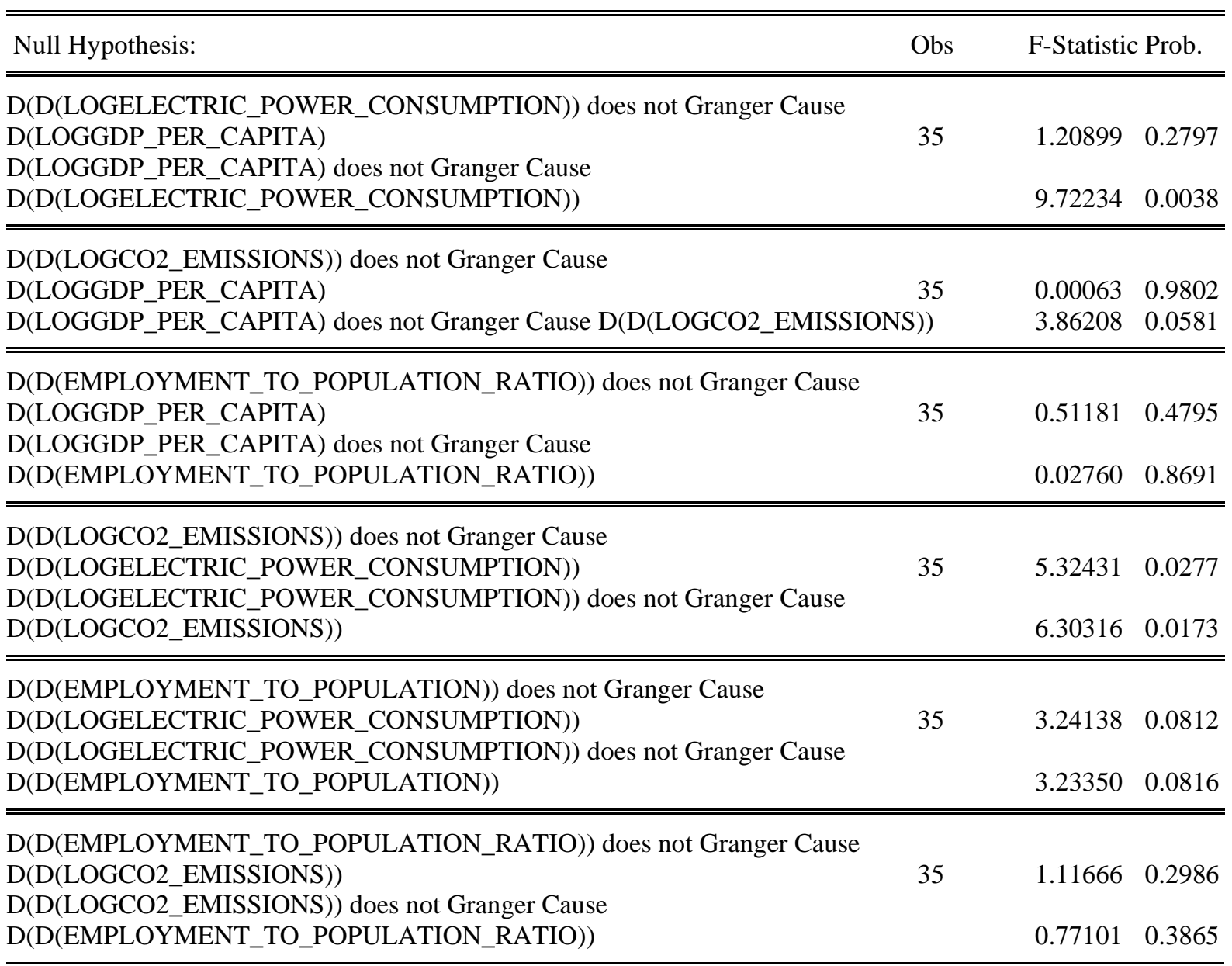


For Japan, the study's findings contradict the findings of Du, Wei, and Cai (2012), who discovered a positive link between $\mathrm{CO} 2$ emissions and Chinese economic growth. The claim of Kasperowicz (2015), on the other hand, that the association between GDP and CO2 emissions is negative, because the development of new low-carbon technologies enables in the long-term obtaining the same output level with lower $\mathrm{CO} 2$ emissions, validates the results of the study. Energy consumption rises with income in emerging market and developing economies, but energy consumption rises with income after the economy reaches a particular level of prosperity in established countries. Furthermore, in the non-high income regime, when both private and domestic credit are used as financial development indicators, energy consumption rises in tandem with financial expansion Chang (2014).

According to the study of Chang (2015), energy consumption continues to increase in advanced economies with high income because they choose to spend their additional income to increase their energy consumption. It also drives the demand for energy upward. One of the reasons why the demand on energy is scaling upward is that they shift the energy use from direct use of fossil fuels to use of higher quality fuels. Since Japan is an advance economy with topnotch technological advancements.

Table 5: Unit root test: China

\begin{tabular}{|c|c|c|c|c|c|c|}
\hline Variable & Level & Prob & $\begin{array}{l}\text { First } \\
\text { Difference }\end{array}$ & Prob & $\begin{array}{l}\text { Second } \\
\text { Difference }\end{array}$ & Prob \\
\hline $\begin{array}{l}\text { Log electric power } \\
\text { consumption per capita }\end{array}$ & 2.137948 & 0.2343 & -1.909333 & 0.3182 & -4.269464 & 0.0090 \\
\hline Log C02 emission & $\begin{array}{l}- \\
1.659237\end{array}$ & 0.4287 & -2.836605 & 0.0802 & -5.634313 & 0.0010 \\
\hline Employment to population ratio & $-\overline{0.678193}$ & 0.8214 & -3.465019 & 0.0278 & -5.561509 & 0.0011 \\
\hline Log GDP per capita & $\begin{array}{l}- \\
1.817251\end{array}$ & 0.3566 & -1.486173 & 0.5085 & -3.252049 & 0.0420 \\
\hline
\end{tabular}

Table 5 shows the results of the unit root test for China at level, first difference, and second difference. Table 6 shows that the second difference of $\log \mathrm{CO} 2$ emissions has a negative significant relationship and the second difference of log electric power consumption has a positively significant relationship to second difference of log GDP per capita in China. When CO2 emission increases, GDP per capita decreases, while when electric power consumption increases, GDP per capita increases as well. Results show that there is no multicollinearity as shown by the VIF and the regression residual achieved normality as shown by the Jarque-Bera stat. Moreover, there is no autocorrelation error as shown by the Durbin-Watson stat and no serial correlation as shown by the Breusch-Godfrey Serial Correlation LM Test. Additionally, results show that there is no heteroskedasticity error encountered in the regression as shown by the Heteroskedasticity Breusch-Pagan-Godfrey test and the ARCH test. Lastly, there is no structural breakpoint in the results as shown by the Chow breakpoint test and there is no misspecification error encountered in the regression as shown by the RAMSEY Reset test.

Table 6: Regression results: China

Dependent Variable: D(D(LOGGDP_PER_CAPITA))

Sample (adjusted): 20022014

\begin{tabular}{lllll}
\hline \hline Variable & Coefficient Std. Errort-Statistic & Prob. & VIF \\
& & & & \\
\hline \hline Constant & -0.033723 & $0.007734-4.360369$ & 0.0018 & NA \\
D(D(LOGELECTRIC_POWER_CONSUMPTION) $)$ & 0.430442 & 0.0912954 .714845 & 0.0011 & 1.659686 \\
D(D(LOGCO2_EMISSIONS)) & -0.191458 & $0.065569-2.919933$ & 0.0170 & 2.161380 \\
D(D(EMPLOYMENT_TO_POPULATION_RATIO)) & -0.011980 & $0.007534-1.590113$ & 0.1463 & 1.462987 \\
& & & & \\
\hline \hline
\end{tabular}




$\begin{array}{lccc} & & & 0.000480 \\ \text { Adjusted R-squared } & 0.642890 & \text { S.D. dependent var } & 0.015160 \\ & & & - \\ \text { S.E. of regression } & 0.009060 & \text { Akaike info criterion } 6.322311 \\ & & & - \\ \text { Sum squared resid } & 0.000739 & \text { Schwarz criterion } & 6.148481 \\ & & \text { Hannan-Quinn } & - \\ \text { Log likelihood } & 45.09502 & \text { criter. } & 6.358041 \\ \text { F-statistic } & 8.201020 & \text { Durbin-Watson stat } & 1.533904 \\ \text { Prob(F-statistic) } & 0.006086 & & \\ \text { Jarque-Bera Stat } & 0.363050 & & \\ \text { Prob(Jarque-Bera) } & 0.833997 & & \end{array}$

Breusch-Godfrey Serial Correlation LM Test:

Null hypothesis: No serial correlation at up to 1 lag

F-statistic

0.354536 Prob. $\mathrm{F}(1,8)$

0.5680

Heteroskedasticity Test: Breusch-Pagan-Godfrey

Null hypothesis: Homoskedasticity

F-statistic

$0.837940 \quad$ Prob. $F(3,9)$

0.5064

Heteroskedasticity Test: ARCH

$\begin{array}{lrrr}\text { F-statistic } & 0.588602 & \text { Prob. F }(1,10) & 0.4607\end{array}$

Chow Breakpoint Test: 2008

Null Hypothesis: No breaks at specified breakpoints

$\begin{array}{llll}\text { F-statistic } & 2.240141 & \text { Prob. F(4,5) } & 0.1999\end{array}$

Ramsey RESET Test

t-statistic

F-statistic

Likelihood ratio

\begin{tabular}{llc} 
Value & df & Probability \\
\hline $1.944624 \quad 8$ & 0.0877 \\
$3.781561(1,8)$ & 0.0877 \\
$5.032223 \quad 1$ & 0.0249
\end{tabular}

Table 7 shows that there is no causation between first difference of log electric power consumption and second difference of log GDP per capita in China. Similarly, there is no causation between first difference log employment to population ratio and second difference of log GDP per capita. However, second difference of log GDP per capita Granger cause first difference of $\log \mathrm{CO} 2$ emissions. The findings are in accordance with those of Aliero and Ibrahim (2012), who discovered a dearth of correlation between aggregate energy consumption and economic growth in the United States, France, England, and China. The findings are similarly consistent with the findings of according to Law, Mustapha, Hashim, and Azlina (2014), GDP is substantial, but only at a modest level in Malaysia. The implication of this study is that minimizing emission will not affect economic growth. This result suggests that reducing $\mathrm{CO} 2$ emissions may have a detrimental influence on economic growth, if there is a causation link between emissions and economic growth.

Table 7: Granger causality: China

Sample: 20002014

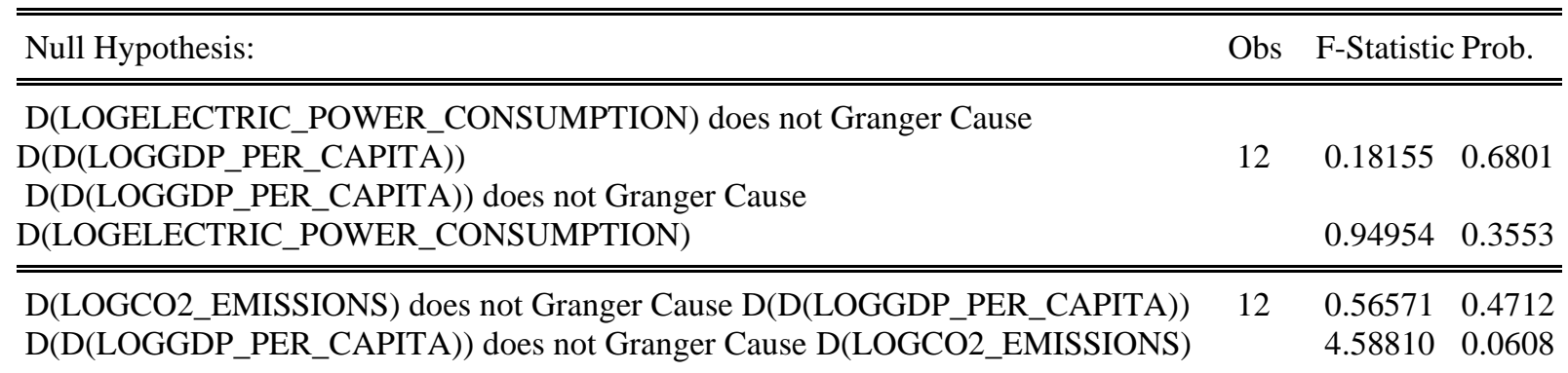


D(EMPLOYMENT_TO_POPULATION_RATIO) does not Granger Cause

D(D(LOGGDP_PER_CAPITA $))$

$12 \quad 0.00029 \quad 0.9867$

D(D(LOGGDP_PER_CAPITA)) does not Granger Cause

D(EMPLOYMENT_TO_POPULATION)

$0.00272 \quad 0.9596$

D(LOGCO2_EMISSIONS) does not Granger Cause

D(LOGELECTRIC_POWER_CONSUMPTION)

$13 \quad 1.06451 \quad 0.3265$

D(LOGELECTRIC_POWER_CONSUMPTION) does not Granger Cause

D(LOGCO2_EMISSIONS)

$2.03621 \quad 0.1841$

D(EMPLOYMENT_TO_POPULATION) does not Granger Cause

D(LOGELECTRIC_POWER_CONSUMPTION)

$13 \quad 1.00178 \quad 0.3405$

D(LOGELECTRIC_POWER_CONSUMPTION) does not Granger Cause

D(EMPLOYMENT_TO_POPULATION)

$0.58370 \quad 0.4625$

D(EMPLOYMENT_TO_POPULATION) does not Granger Cause

D(LOGCO2_EMISSIONS)

$13 \quad 1.94477 \quad 0.1934$

D(LOGCO2_EMISSIONS) does not Granger Cause

D(EMPLOYMENT_TO_POPULATION)

$2.69730 \quad 0.1315$

Table 8: Unit root test: Korea

\begin{tabular}{lllllll}
\hline Variable & Level & Prob & $\begin{array}{l}\text { First } \\
\text { Difference }\end{array}$ & Prob & $\begin{array}{l}\text { Second } \\
\text { Difference }\end{array}$ & Prob \\
\hline $\begin{array}{l}\text { Log electric power consumption } \\
\text { per capita }\end{array}$ & - & & & & -3.856721 & 0.0063 \\
Log C02 emission & - & & & & & \\
& 2.571139 & 0.1084 & -4.216199 & 0.0021 & -6.217838 & 0.0000 \\
Employment to population ratio & - & & & & & \\
& 3.874505 & 0.0052 & -6.055028 & 0.0000 & -6.213811 & 0.0000 \\
Log GDP per capita & - & & & -5.593667 & 0.0000 & \\
& 3.748897 & 0.0077 & -0.954527 & 0.7571 & & 0.0042 \\
\hline
\end{tabular}

Table 8 shows the results of the unit root test for Japan at level, first difference, and second difference. As a result for Korea,with the increasing $\mathrm{CO} 2$ emissions and electric power use, GDP per capita increases as well. This is consistent with the findings of Du, Wei, and Cai (2012), who discovered a positive link between $\mathrm{CO} 2$ emissions and Chinese economic development. According to the data of Esen and Bayrak (2017), energy consumption has a positive and statistically significant impact on economic growth. This effect undermines as the level of development (income) results in an increase, indicating that countries use their energy resources more effectively and efficiently as their level of development increases, and that they keep the energy required per unit product low, resulting in more output with less energy consumption for 75 net energy importing countries. The results are in contrast Pata's (2018) study, which found that pollution in Turkey rose with socioeconomic level. According to Maitah, Kuzmenko, and Toth (2015), a 2\% rise in GDP translates in a 1\% decrease in unemployment. Analytical studies demonstrate that a $2 \%$ increase in GDP per capita results in a $1 \%$ increase in employment rate. The latter might be thought of as an extension of Okun's law.

In the study of Du, Wei and Cai (2012), there is positive relationship between GDP per capita, CO2 emissions and electric power use. According to the findings in study, both per capita and aggregate $\mathrm{CO} 2$ emissions of China will keep on increasing over the next decade if they prioritize the economic development. The government of China can take more active actions to lessen $\mathrm{CO} 2$ emissions. In the study of Esen and Bayrak (2017), energy consumption and economic growth has a positive relationship because energy is important in increasing the welfare level of society. While in the study of Pata (2018) in Turkey they found that CO2 emissions increases when the welfare level of society increases. According to the study of Maitah, Kuzmenko, and Toth (2015), an increase in GDP per capita leads to an increase in employment rate. Most of the countries that have low unemployment rate considered one of the richest countries in the world. 
Table 9 shows that the second difference of $\log \mathrm{CO} 2$ emissions and the second difference of $\log$ electric power consumption have positively significant relationship to first difference of log GDP per capita in Korea. When $\mathrm{CO} 2$ emission and electric power consumption increases, GDP per capita increases as well. While second difference of employment to population ratio has a negative significant relationship to first difference of log GDP per capita. Results show that there is no multicollinearity as shown by the VIF and the regression residual achieved normality as shown by the Jarque-Bera stat. Moreover, there is no autocorrelation error as shown by the Durbin-Watson stat and no serial correlation as shown by the Breusch-Godfrey Serial Correlation LM Test. Additionally, results show that there is no heteroskedasticity error encountered in the regression as shown by the Heteroskedasticity Breusch-Pagan-Godfrey test and the ARCH test. However, there is structural breakpoint in the results as shown by the Chow breakpoint test and there is misspecification error encountered in the regression as shown by the RAMSEY Reset test. According to the results of the study of Du, Wei, and Cai (2012), if the policy variables remain at 2009 levels with little to no government intervention, China's per capita $\mathrm{CO} 2$ emissions are projected to reach 9.03 and $11.49 \mathrm{t}$ by 2015 and 2020, respectively, while the results of the Current Policy scenario show that, if the government's current energy conservation targets are met, China's per capita $\mathrm{CO} 2$ emissions are expected to reach 9.03 and 11.49 t by 2015 and 2020, respectively.

Table 9: Regression results: Korea

Dependent Variable: D(LOGGDP_PER_CAPITA)

Sample: 19812014

\begin{tabular}{|c|c|c|c|c|}
\hline Variable & Coefficient & Std. Error t-Statistic & Prob. & VIF \\
\hline Constant & 0.223672 & 0.0936152 .389284 & 0.0234 & NA \\
\hline D(D(LOGELECTRIC_POWER_CONSUMPTION)) & 0.455676 & 0.1135674 .012405 & 0.0004 & 2.771747 \\
\hline $\mathrm{D}(\mathrm{D}(\mathrm{LOGCO} 2$ EMISSIONS $))$ & 0.174187 & 0.0916401 .900770 & 0.0670 & 2.704650 \\
\hline \multirow[t]{2}{*}{ D(D(EMPLOYMENT_TO_POPULATION_RATIO)) } & -0.003542 & $0.001579-2.243249$ & 90.0324 & 1.044882 \\
\hline & 0.766339 & $\begin{array}{l}\text { Mean dependent } \\
\text { var }\end{array}$ & 0.056925 & \\
\hline Adjusted R-squared & 0.742972 & $\begin{array}{l}\text { S.D. dependent var } \\
\text { Akaike info }\end{array}$ & 0.034944 & \\
\hline S.E. of regression & 0.017716 & criterion & -5.118580 & \\
\hline Sum squared resid & 0.009416 & $\begin{array}{l}\text { Schwarz criterion } \\
\text { Hannan-Quinn }\end{array}$ & -4.939008 & \\
\hline Log likelihood & 91.01585 & criter. & -5.057340 & \\
\hline F-statistic & 32.79697 & Durbin-Watson stat & t 2.022097 & \\
\hline Prob(F-statistic) & 0.000000 & & & \\
\hline Jarque-Bera Stat & 0.982709 & & & \\
\hline Prob(Jarque-Bera) & 0.611797 & & & \\
\hline
\end{tabular}

Breusch-Godfrey Serial Correlation LM Test:

Null hypothesis: No serial correlation at up to $1 \mathrm{lag}$

F-statistic

$0.013452 \quad$ Prob. $\mathrm{F}(1,29)$

0.9085

Heteroskedasticity Test: Breusch-Pagan-Godfrey

Null hypothesis: Homoskedasticity

F-statistic

2.197937 Prob. F(3,30)

0.1089

Heteroskedasticity Test: ARCH

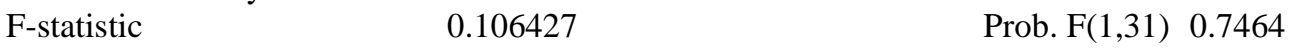

Chow Breakpoint Test: 1998

Null Hypothesis: No breaks at specified breakpoints

F-statistic 4.147995

Prob. F $(4,26) 0.0099$

Ramsey RESET Test

t-statistic

\begin{tabular}{llc} 
Value & df & Probability \\
\hline 3.605916 & 29 & 0.0012
\end{tabular}


F-statistic DOI: https://doi.org/10.47405/mjssh.v6i11.1134

Likelihood ratio

$13.00263(1,29)$

0.0012

$12.59484 \quad 1$

0.0004

Table 10 shows the cointegration results for Korea indicating that the variables are cointegrated in the long-run as shown in the Trace statistic. This shows that the variables are related in the long-run and can be use in the regression. Table 11 shows that there is no causation between first difference log GDP per capita and first difference log electric power consumption in Korea. Similarly, there is no causation between first difference log GDP per capita employment to population ratio. However, there is two-way causation between first difference log GDP per capita and first difference of log electric power consumption. According to the analysis, there is no indications of a link between GDP and energy consumption. The outcomes are congruent with those of Aliero and Ibrahim (2012), who discovered a lack of association between aggregate energy use and economic development in the United States, France, England, and China. Saboori and Sulaiman (2013), on the other hand, identified bi-directional Granger causation relationships between economic growth and energy use in Indonesia, Malaysia, and the Philippines. According to Maitah, Kuzmenko, and Toth (2015), a 2\% gain in GDP results in a $1 \%$ decrease in unemployment. Analytical studies indicate that a $2 \%$ increase in GDP per capita correlates in a $1 \%$ increase in employment rate. The latter could be viewed as an extension of Okun's law.

Table 10: Cointegration Test: Korea

\begin{tabular}{|c|c|c|c|c|}
\hline $\begin{array}{l}\text { Hypothesized } \\
\text { No. of CE(s) }\end{array}$ & $\begin{array}{l}\text { Trace } \\
\text { Statistic }\end{array}$ & Prob.** & $\begin{array}{l}\text { Max-Eigen } \\
\text { Statistic }\end{array}$ & Prob.** \\
\hline None $*$ & 103.2685 & 0.0000 & 64.59629 & 0.0000 \\
\hline At most $1 *$ & 38.67221 & 0.0037 & 21.47198 & 0.0448 \\
\hline At most $2 *$ & 17.20023 & 0.0274 & 10.45772 & 0.1836 \\
\hline At most $3 *$ & 6.742512 & 0.0094 & 6.742512 & 0.0094 \\
\hline
\end{tabular}

Sample: 19772014

Table 11: Granger causality: Korea

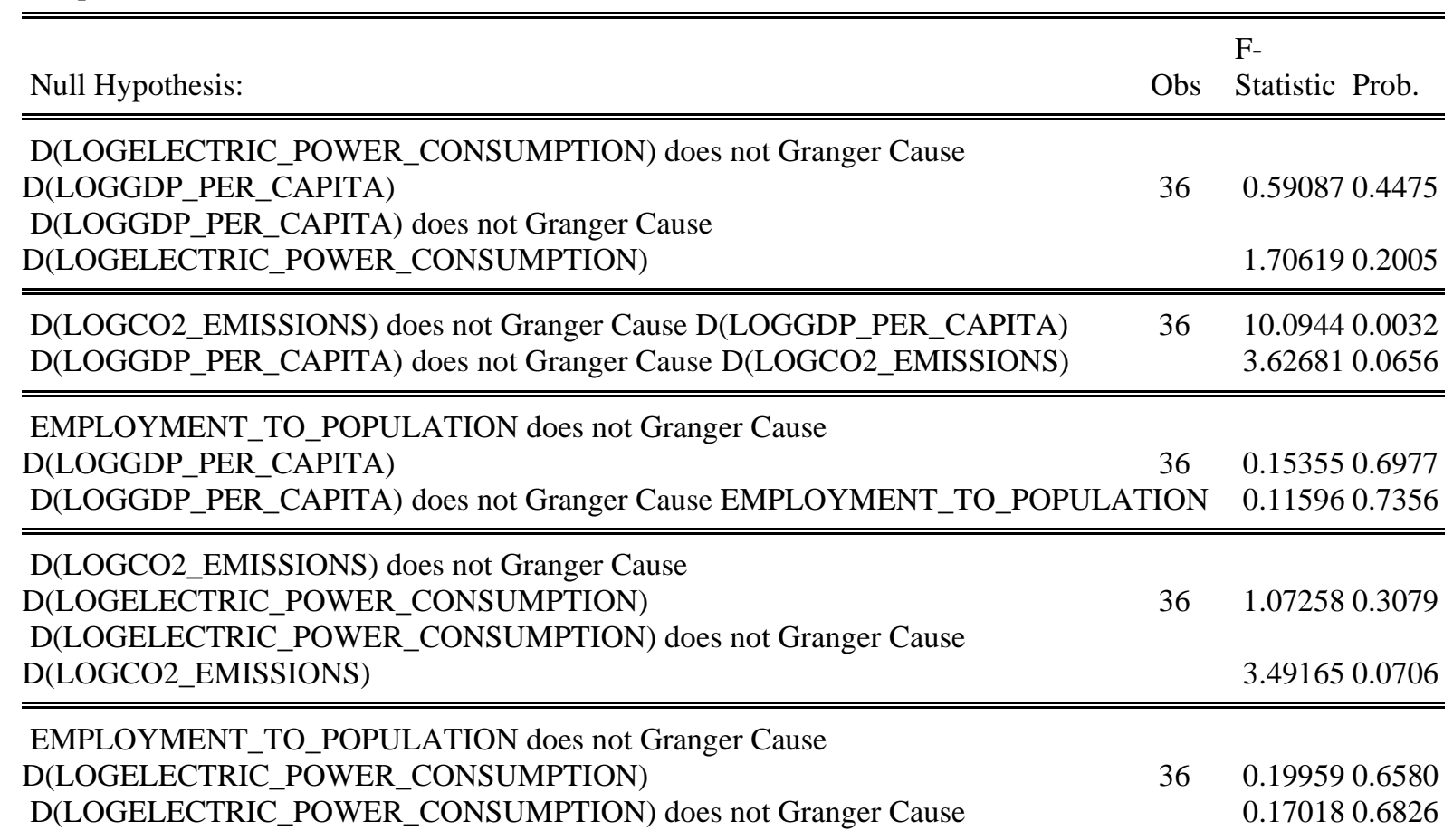




\section{Conclusion}

This study investigated the relationship between CO2 emissions and GDP per capita of the three East Asian countries (China, Japan and Korea) by using multiple regression analysis and cointegration tests from the year 1977-2014 for Japan and Korea, and 2000-2014 for China. The results show that Japan's $\mathrm{CO} 2$ emissions and employment to population ratio has a positive relationship to GDP per capita. When $\mathrm{CO} 2$ emissions and employment to population ratio increase, the GDP per capita also increases. Based on the study's findings for Japan, it contradicts the study of Du, Wei and Cai, who said that there is a positive relationship between $\mathrm{CO} 2$ emissions and Chinese economic growth. Japan's energy consumption continues to increase because of their advance economy with high income and the said country is known for their topnotch technological equipment. As for China, results show that $\mathrm{CO} 2$ emissions has a negative relationship to GDP per capita, while electric power consumption has a positive relationship to GDP per capita. When the $\mathrm{CO} 2$ emissions increases, GDP per capita decreases, while when electric power increases, GDP per capita also increases. As for the country of Korea, results show that $\mathrm{CO} 2$ emissions and electric power use has a positive link to GDP per capita. When $\mathrm{CO} 2$ emissions and electric power use increases, GDP per capital also increases. It also shows that Korea's employment to population ratio has a negative relationship to GDP per capita. There is no indication of link between GDP per capita and electric power consumption in Korea.

\section{References}

Aichele, R., \& Felbermayr, G. (2012). Kyoto and the carbon footprint of nations. Journal of Environmental Economics and Management, 336-354.

Aliero, H., \& Ibrahim, S. (2012). The Relationship between Energy Consumption and Economic Growth in Nigeria A Causality Analysis. International Journal of Marketing and Technology, $1-14$.

Almer, C., \& Winkler, R. (2012). The Effect of Kyoto Emission Targets on Domestic CO2 Emissions: A Synthetic Control Approach. 1-29.

Alshehry, A., \& Belloumi, M. (2015). Energy Consumption, Carbon Dioxide Emissions and Economic Growth: The Case of Saudi Arabia. Renewable and Sustainable Energy Reviews, 237-247.

Azam, M., Khan, A., Abdullah, H., \& Qureshi, M. (2016). The impact of CO2 emissions on economic growth: evidence from selected higher $\mathrm{CO} 2$ emissions economies. Environmental Science and Pollution Research International, 6376-6389.

Beşe, E., \& Kalayci, S. (2018). Environmental Kuznets curve (EKC): Empirical relationship between economic growth, energy consumption, and $\mathrm{CO} 2$ emissions: Evidence from 3 developed countries. Panoeconomicus.

Cai, Y., Newth, D., Finnigan, J., \& Gunasekera, D. (2015). A hybrid energy-economy model for global integrated assessment of climate change, carbon mitigation and energy transformation. Applied Energy, 381-395.

Carvalho, T., \& de Almeida, E. (2011). The Global Environmental Kuznets Curve and the Kyoto Protoco. 1-22.

Chang, S.-C. (2015). Effects of financial developments and income on energy consumption. International Review of Economics \& Finance, 28-44.

Cohen, G., Jalles, J., Loungani, P., \& Marto , R. (2017). Emissions and Growth: Trends and Cycles in a Globalized World. International Monetary Fund, 1-56.

Du, L., Wei, C., \& Cai, S. (2012). Economic development and carbon dioxide emissions in China: Provincial panel data analysis. China Economic Review, 371-384. 
Ejuvbekpokpo, S. (2014). Impact of Carbon Emission on Economic Growth in Nigeria. Asian Journal of Basic and Applied Sciences, 15-55.

Esen, Ö., \& Bayrak, M. (2017). Does more energy consumption support economic growth in net energy-importing countries? Journal of Economics, Finance and Administrative Science, 75-98.

Farabi, A., Abdullah, A., \& Setianto, R. (2019). Energy Consumption, Carbon Emissions and Economic Growth in Indonesia and Malaysia. International Journal of Energy Economics and Policy, 338-345.

Galeotti, M., \& Lanza, A. (1999). Richer and cleaner? A study on carbon dioxide emissions in developing countries. Energy Policy, 565-573.

Grossman, G. M., \& Krueger, A. B. (1994). Economic Growth and the Environment. National Bureau of Economic Research Working Paper Series.

Grunewald, N., \& Zarzoso, I. (2010). Carbon Dioxide Emissions, Economic Growth and the Impact of the Kyoto Protocol. 1-26.

Hasanov, F. J., Mikayilov, J. I., Mukhtarov, S., \& Suleymanov, E. (2019). Does CO2 emissionseconomic growth relationship reveal EKC in developing countries? Evidence from Kazakhstan. Environmental Science and Pollution Research, 30229-30241.

Hovi, J., Skodvin, T., \& Andresen, S. (2009). The Persistence of the Kyoto Protocol: Why Other Annex I Countries Move on Without the United States. Global Environmental Politics, 1-23.

Işık, C., \& Shahbaz, M. (2015). Energy Consumption and Economic Growth: A Panel Data Aproach to OECD Countries. International Journal of Energy Science, 1-5.

Jakeman, G., \& Fisher, B. S. (2006). Benefits of Multi-Gas Mitigation: An Application of the Global Trade and Environment Model (GTEM). The Energy Journal, 323-342.

Jalles, J., \& Ge, J. (2020). Emissions and economic development in commodity exporting countries. Energy Economics, 1-14.

Jorgenson, A. K., \& Huang, X. (2018). The Asymmetrical Effects of Economic Development on Consumption-based and Production-based Carbon Dioxide Emissions, 1990 to 2014. Socius: Sociological Research for a Dynamic World, 1-10.

Kapsos, S. (2006). The Employment Intensity of Growth: Trends and Macroeconomic Determinants. Labor Markets in Asia, 143-201.

Kasperowicz, R. (2015). Economic growth and CO2 emissions:. Journal of International Studies, 9198.

Kitov, I., \& Kitov, O. (2011). Employment, Unemployment and Real Economic Growth. 1-15.

Koçak, E., Bulut, Ü., \& Bilgili, F. (2016). The Dynamic Impact of Renewable Energy Consumption on $\mathrm{CO} 2$ Emissions: A Revisited Environmental Kuznets Curve Approach. Renewable and Sustainable Energy Reviews, 838-845.

Korppoo, A. (2013). Does Doha's decision treat transition economies unequally? Climate Policy, 403407.

Law, S., Mustapha, N., Hashim, N., \& Azlina, A. (2014). Dynamic linkages among transport energy consumption, income and CO2 emission in Malaysia. Energy Policy, 598-606.

Li, X., Liu, J., Xu, H., Zhong, P., Zheng, X., Wang, Z., \& Zhao, J. (2011). Calculation of endogenous carbon dioxide emission during highway tunnel construction: A case study. 2011 International Symposium on Water Resource and Environmental Protection, 2260-2264.

Maitah, M., Kuzmenko, E., \& Toth, D. (2015). he Effect of GDP per Capita on Employment Growth in Germany, Austria and the Czech Republic: Macroeconomic Analysis. Review of European Studies, 240-251.

Mansoor, A., \& Sultana, B. (2018). Impact of Population, GDP and Energy Consumption on Carbon Emissions: Evidence from Pakistan Using an Analytic Tool IPAT. Asian Journal of Economics and Empirical Research, 183-190.

Mi, R., Ahammad, H., Hitchins, N., \& Heyhoe, E. (2012). Development and deployment of clean electricity technologies in Asia: A multi-scenario analysis using GTEM. Energy Economics, 399-409.

Mohanty, A., \& Chaturvedi, D. (2014). Relationship between Electricity Energy Consumption and GDP: Evidence from India. International Journal of Economics and Finance, 186-202.

Narayan, P., \& Popp, S. (2012). The energy consumption-real GDP nexus revisited: Empirical evidence from 93 countries. Economic Modelling, 303-308. 
Nguyen, A. (2019). The Relationship between Economic Growth, Energy Consumption and Carbon Dioxide. Eurasian Journal of Business and Economics, 1-15.

Owusu, P., \& Sarkodie, S. (2016). Carbon dioxide emissions, GDP per capita, industrialization and population: An evidence from Rwanda. Environmental Engineering Research, 116-124.

Ozturk, I., Aslan, A., \& Kalyoncu, H. (2010). Energy consumption and economic growth relationship: Evidence from panel data for low and middle income countries. Energy Policy, 4422-4428.

Pata, U. (2018). Renewable energy consumption, urbanization, financial development, income and $\mathrm{CO} 2$ emissions in Turkey: Testing EKC hypothesis with structural breaks. Journal of Cleaner Production, 770-779.

Peters, G. P., Aamaas, B., Berntsen, T., \& Fuglestvedt, J. S. (2011). The integrated global temperature change potential (iGTP) and relationships between emission metrics. Environmental Research Letters, $1-9$.

Richmond, A. K., \& Kaufmann, R. K. (2006). Is there a turning point in the relationship between income and energy use and/or carbon emissions? Ecological Economics, 176-189.

Saboori, B., \& Sulaiman, J. (2013). CO2 emissions, energy consumption and economic growth in Association of Southeast Asian Nations (ASEAN) countries: A cointegration approach. Energy, 813-822.

Saidi, K., \& Hammami, S. (2015). The impact of CO2 emissions and economic growth on energy consumption in 58 countries. Energy Reports, 62-70.

Salim, R., Rafiq, S., \& Shafiei, S. (2017). Urbanization, Energy Consumption, and Pollutant Emission in Asian Developing Economies : An Empirical Analysis. ADBI Working Paper Series, 1-24.

Streck, C., Keenlyside, P., \& Unger, M. (2016). The Paris Agreement: A New Beginning. journal for european environmental \& planning law, 3-29.

Thongrawd, C., \& Kerdpitak, C. (2020). ENERGY CONSUMPTION, CO2 EMISSION AND ECONOMIC GROWTH IN ASEAN COUNTRIES. Journal of Security and Sustainability Issues, 12-27.

Wang, C.-H., Ko, M.-H., \& Jiun, C. (2019). Effects of Kyoto Protocol on CO2 Emissions: A FiveCountry Rolling Regression Analysis. Sustainability, 1-20.

Winning, M., Price, J., Ekins, P., Pye, S., Glynn, J., Watson, J., \& McGlade, C. (2019). Nationally Determined Contributions under the Paris Agreement and the costs of delayed action. Climate Policy, 947-958.

Yildirim, H. (2017). Economic Growth and CO2 Emissions for OECD Countries. International Journal of Management Science, 30-37.

Young, O. R. (2016). The Paris Agreement: Destined to Succeed or Doomed to Fail? Politics and Governance, 124-132.

Yusuf, A., Abubakar, A., \& Mamman, S. (2020). Relationship between greenhouse gas emission, energy consumption, and economic growth: evidence from some selected oil-producing African countries. Environmental Science and Pollution Research, 15815-15823. 